\title{
Identifying a Heart Rate Recovery Criterion After a 6-Minute Walk Test in COPD
}

\author{
Dongxing Zhao (D) ${ }^{1,2}$ \\ Asghar Abbasi' \\ Richard Casaburi (iD) \\ Alessandra Adami $\mathbb{D D}^{3}$ \\ Nicholas B Tiller' \\ Wei Yuan ${ }^{1,4}$ \\ Christopher Yee $^{5}$ \\ Nicholas G Jendzjowsky' \\ David M MacDonald ${ }^{6,7}$ \\ Ken M Kunisaki ${ }^{6,7}$ \\ William W Stringer \\ Janos Porszasz' \\ Barry J Make ${ }^{8}$ \\ Russell P Bowler ${ }^{8}$ \\ Harry B Rossiter (D) \\ On behalf of the \\ COPDGene Investigators
}

'Rehabilitation Clinical Trials Center,

Division of Respiratory and Critical Care

Physiology and Medicine, The Lundquist

Institute for Biomedical Innovation at

Harbor-UCLA Medical Center, Torrance,

CA, USA; ${ }^{2}$ State Key Laboratory of

Respiratory Disease, National Clinical

Research Center for Respiratory Disease

Guangzhou Institute of Respiratory Health,

The First Affiliated Hospital of Guangzhou

Medical University, Guangzhou, Guangdong,

510120, People's Republic of China;

${ }^{3}$ Department of Kinesiology, University of

Rhode Island, Kingston, RI, USA;

${ }^{4}$ Respiratory Medicine Department, Beijing

Friendship Hospital Affiliated of Capital

Medical University, Beijing, I00050, People's

Republic of China; ${ }^{5}$ MemorialCare Long

Beach Medical Center, Long Beach, CA,

USA; ' ${ }^{6}$ ivision of Pulmonary, Allergy,

Critical Care and Sleep Medicine, University

of Minnesota, Minneapolis, MN, USA;

${ }^{7}$ Minneapolis VA Health Care System,

Minneapolis, MN, USA; ${ }^{8}$ National Jewish

Health, Denver, CO, USA

Correspondence: Harry B Rossiter

Email hrossiter@ucla.edu
Background: Slow heart rate recovery (HRR) after exercise is associated with autonomic dysfunction and increased mortality. What HRR criterion at 1-minute after a 6-minute walk test (6MWT) best defines pulmonary impairment?

Study Design and Methods: A total of 5008 phase 2 COPDGene (NCT00608764) participants with smoking history were included. A total of 2127 had COPD and, of these, 385 were followed-up 5-years later. Lung surgery, transplant, bronchiectasis, atrial fibrillation, heart failure and pacemakers were exclusionary. HR was measured from pulse oximetry at end-walk and after 1-min seated recovery. A receiver operator characteristic (ROC) identified optimal HRR cut-off. Generalized linear regression determined HRR association with spirometry, chest CT, symptoms and exacerbations.

Results: HRR after 6MWT (bt/min) was categorized in quintiles: $\leq 5$ (23.0\% of participants), $6-$ 10 (20.7\%), 11-15 (18.9\%), 16-22 (18.5\%) and $\geq 23(18.9 \%)$. Compared to HRR $\leq 5, H R R \geq 11$ was associated with $(\mathrm{p}<0.001)$ : lower pre-walk HR and 1-min post HR; greater end-walk HR; greater 6MWD; greater $\mathrm{FEV}_{1} \%$ pred; lower airway wall area and wall thickness. HRR was positively associated with $\mathrm{FEV}_{1}$ \%pred and negatively associated with airway wall thickness. An optimal HRR $\leq 10 \mathrm{bt} / \mathrm{min}$ yielded an area under the ROC curve of 0.62 (95\% CI $0.58-0.66)$ for identifying $\mathrm{FEV}_{1}<30 \%$ pred. $\mathrm{HRR} \geq 11 \mathrm{bt} / \mathrm{min}$ was the lowest $\mathrm{HRR}$ associated with consistently less impairment in 6MWT, spirometry and CT variables. In COPD, HRR $\leq 10 \mathrm{bt} / \mathrm{min}$ was associated with $(\mathrm{p}<0.001)$ : $\geq 2$ exacerbations in the previous year $(\mathrm{OR}=1.76[1.33-2.34])$; $\mathrm{CAT} \geq 10(\mathrm{OR}=1.42[1.18-1.71]) ; \mathrm{mMRC} \geq 2(\mathrm{OR}=1.42[1.19-1.69]) ; \mathrm{GOLD} 4(\mathrm{OR}=1.98[1.44$ 2.73] $)$ and GOLD $D(O R=1.51[1.18-1.95]) . H R R \leq 10 \mathrm{bt} / \mathrm{min}$ was predicted COPD exacerbations at 5-year follow-up $(\mathrm{RR}=1.83[1.07-3.12], \mathrm{P}=0.027)$.

Conclusion: HRR $\leq 10 \mathrm{bt} / \mathrm{min}$ after $6 \mathrm{MWT}$ in COPD is associated with more severe expiratory flow limitation, airway wall thickening, worse dyspnoea and quality of life, and future exacerbations, suggesting that an abnormal $\mathrm{HRR} \leq 10 \mathrm{bt} / \mathrm{min}$ after a $6 \mathrm{MWT}$ may be used in a comprehensive assessment in COPD for risk of severity, symptoms and future exacerbations. Keywords: autonomic dysfunction, chest computed tomography, COPD exacerbation, exercise, spirometry

\section{Background}

Chronic obstructive pulmonary disease (COPD) is associated with autonomic dysfunction $^{1,2}$ that predicts increased mortality. ${ }^{3,4}$ Heart rate recovery (HRR) after exercise is an easily-acquired measure of autonomic dysfunction. ${ }^{5}$ Abnormal HRR after maximal exercise, such as a cardiopulmonary exercise test (CPET), predicts overall mortality in various populations, ${ }^{5-7}$ and associates with pulmonary function abnormalities. ${ }^{8}$ In addition, in COPD, prevalence of impaired HRR increases with greater GOLD-defined severity of expiratory flow limitation. ${ }^{9}$ 
The 6-minute walk test (6MWT) is a simple test of functional performance that is used widely in COPD patient assessment. Six-minute walk distance (6MWD) associates negatively with COPD hospitalizations, exacerbations and mortality ${ }^{10}$ and also predicts survival in patients with heart failure, ${ }^{11}$ idiopathic pulmonary fibrosis ${ }^{12}$ and pulmonary hypertension. ${ }^{13}$ Previous studies used values of $\leq 12, \leq 13, \leq 14$ or $\leq 16 \mathrm{bt} / \mathrm{min}$ as criterion to identify abnormal HRR in cardiovascular disease patients, ${ }^{5,12,14}$ but a criterion to define a suitable HRR cutoff after 6MWT in COPD is not well established.

A previous study indicated that $\mathrm{HRR} \leq 14 \mathrm{bt} / \mathrm{min}$ after a symptom-limited incremental exercise test strongly predicted mortality in 147 COPD patients. ${ }^{7}$ Rodriguez et al found, in $101 \mathrm{COPD}$ patients, that $\mathrm{HRR} \leq 14 \mathrm{bt} / \mathrm{min}$ after 6MWT associated with higher exacerbation risk during the subsequent 12 months. ${ }^{15}$ Criteria defining normality in these studies were based on small sample sizes $(<150$ COPD patients) $)^{7,15}$ and were not associated with pulmonary function or symptoms. ${ }^{15}$ In COPD, exercise may be limited by respiratory symptoms prior to reaching cardiovascular limits, often with substantial heart rate reserve; therefore, COPD patients with more severe obstruction or greater symptom burden may exhibit lower HRR following a 6MWT. Furthermore, autonomic function may be associated with changes that affect vagal afferent innervation of the respiratory tract ${ }^{16,17}$ reflected in anatomic chest $\mathrm{CT}$ variables. Establishing a criterion HRR following 6MWT in COPD that is associated with lung function, dyspnoea and quality of life and future exacerbations (as opposed to cut-offs established in other disease states or testing modalities) has the potential to provide insight into health status and guide management. We therefore aimed to identify an HRR abnormality criterion after 6MWT that associated independently with COPD, COPD severity, symptoms, and predicted future exacerbations. To achieve this, we analysed data from the longitudinal cohort study, the Genetic Epidemiology of COPD (COPDGene).

\section{Methods}

\section{Study Design and Population}

This was a retrospective analysis of COPDGene ${ }^{18}$ (NCT00608764) participants at 5 years (phase 2; 20122017) and 10 years (Phase 3; 2017-2019) after their initial study visit. The 5 -year visit was the first visit at which HRR was recorded. COPDGene enrolled current and former smokers with $\geq 10$ pack-years smoking history and never smokers. Participants were either Non-Hispanic White or African American and aged 45-90 years at their 5-year visit. A detailed description of the study design and inclusion/exclusion criteria is available. ${ }^{18}$ Those with complete 6MWT and lung function data were included in the analysis and those with lung surgery, transplant, bronchiectasis, atrial fibrillation, heart failure, and pacemakers were excluded. Participants underwent 6MWT, post-bronchodilator spirometry, quantitative computed tomography (CT), and questionnaires to assess symptoms and medical history. The COPDGene protocol was approved by institutional review boards at 21 participating centres (see online supplement) and conducted in accordance with the Declaration of Helsinki. Written informed consent was obtained from all participants.

\section{Measurements}

6MWT was performed at all sites according to ATS guidelines $^{19}$ and as described in the COPDGene manual of procedures. Heart rate and $\mathrm{SpO}_{2}$ were measured using a pulse oximeter after 10 minutes of seated rest prior to the walk, immediately at walk's end, and 1-minute after the end of the walk. At the end of the walk, participants were seated as quickly but as safely as possible. HRR (independent variable) was defined as the difference in HR between end-walk and 1-min recovery. HRR grades were identified according to quintiles of HRR: HRR $\leq 5 \mathrm{bt} / \mathrm{min}, 6-10 \mathrm{bt} /$ $\mathrm{min}, 11-15 \mathrm{bt} / \mathrm{min}, 16-22 \mathrm{bt} / \mathrm{min}$ and HRR $\geq 23 \mathrm{bt} / \mathrm{min}$.

Exposures included smoking history, exacerbation history, and medication use. Outcome variables included the scores of the modified Medical Research Council dyspnoea questionnaire (mMRC) and COPD assessment test (CAT). Exacerbation frequency during the year prior to the 5-year or 10-year follow-up visits, with exacerbation defined as acute worsening of COPD symptoms that resulted either in prescription of a course of antibiotics or oral corticosteroids, or in hospitalization (ie, moderate or severe exacerbations). ${ }^{20}$ Frequent exacerbations were defined as $\geq 2$ exacerbations in the previous year. ${ }^{20,21}$ Outcomes also included COPD severity, assessed by GOLD spirometric stage, and COPD Group by assessment of symptoms and risk of exacerbations based on the 2020 GOLD guidelines, eg GOLD group D were those with $\mathrm{mMRC} \geq 2$ or $\mathrm{CAT} \geq 10$ and exacerbation frequency $\geq 2$ in the previous year. ${ }^{20}$

Spirometry was performed using an EasyOne ${ }^{\circledR}$ Spirometer (ndd, Zurich, Switzerland) before and after administration of a short-acting $\beta_{2}$-agonist (albuterol) 
according to ATS/ERS recommendations. ${ }^{22}$ Spirometry studies were reviewed centrally by COPDGene to ensure multicentre quality control. ${ }^{18}$ The greatest combined $\mathrm{FEV}_{1}$ and FVC measurements of three acceptable efforts was reported. Lung diffusing capacity for carbon monoxide $\left(\mathrm{D}_{\mathrm{LCO}}\right)$ was measured by using the EasyOne Pro system (ndd Medical Technologies, Inc.) in accordance with European Respiratory Society/American Thoracic Society standards for measurement of single-breath carbon monoxide uptake in the lung. ${ }^{23} \mathrm{D}_{\text {LCO }}$ percent predicted values were calculated by using Global Lung Initiative reference equations, ${ }^{24}$ with $\mathrm{D}_{\mathrm{LCO}}$ values adjusted for haemoglobin and altitude.

Exploratory outcomes included CT scans variables. CT scan at phase 2 COPDGene were performed at full inspiration $(200 \mathrm{mAs})$, and at the end of normal expiration (50 $\mathrm{mAs}) .{ }^{18}$ Airway wall thickening was assessed by segmental airway wall thickness (AWT) calculated as average values in six segmental bronchi, segmental wall area percentage (WA\%=[outer bronchus area-airway luminal area]/outer bronchus area $\times 100$ ) obtained at the same sites as used for airway wall thickness, and the square root of wall area of a $10-\mathrm{mm}$ perimeter airway $\left(\mathrm{Pi}_{10}\right)^{25-27}$ Emphysema percentage was defined as percentage of lung voxels $\leq-950$ Hounsfield units (HU) on an endinspiratory $\mathrm{CT}$ scan, and gas trapping percentage was defined as percentage of lung voxels $\leq-856 \mathrm{HU}$ on expiratory $\mathrm{CT}^{27,28}$

\section{Statistical Analyses}

Data are presented as mean $\pm \mathrm{SD}$, median (interquartile range) or number (percent). Univariate analyses were performed using one-way ANOVA, Kruskal-Wallis tests, independent-samples Student's $t$ or Mann-Whitney test for continuous variables and chi-square test or z-test for proportions, as appropriate. Associations between HRR or HRR quintile (independent variables) and pulmonary function and quantitative CT (dependent variables) were assessed by multivariable generalized linear regression models. Emphysema percentage and gas trapping percentage were natural log transformed to account for skewed distributions. Estimates of linear trend across increasing HRR quintiles were performed by including median of each quintile as a continuous variable (providing a P-fortrend value). The optimal HRR cut-off point (highest sum of sensitivity and specificity) to identify $\mathrm{FEV}_{1}<30 \%$ pred was selected using receiver operating characteristic (ROC) analysis. Relationships between HRR cut-off (independent variable) and exacerbations and symptoms (dependent variables) were assessed by logistic regression models. At the 5-year visit (phase 2) relationships between HRR and exacerbation frequency $\geq 2$ in the previous year, CAT $\geq 10$ and $\mathrm{mMRC} \geq 2$ were assessed. COPD patients with available data were followed-up at the 10-year visit (phase 3), where the relationship between HRR at phase 2 and exacerbations in the year prior to phase 3 was assessed. Multivariable models were adjusted for race, sex, age, body mass index (BMI), smoking history, cardiovascular disease (CVD) history and (for CT measures) CT scanner type. All statistical analyses were performed using SPSS (IBM SPSS V.25.0, Armonk, NY, USA). Alpha level was set at $\mathrm{P}<0.05$, with Bonferroni correction where needed to account for multiple comparisons. Figures were created using GraphPad Software (GraphPad Prism V.8.0 for Windows, San Diego, California USA).

\section{Results \\ Subject Characteristics}

10,311 non-Hispanic white and African American participants were initially enrolled in COPDGene (phase 1). Of these, 6758 were followed-up at phase 2 (5-year visit). Of those, 1750 were excluded from this analysis (Figure 1): 876 of these did not conduct 6MWT or spirometry; and 874 were excluded on the basis of history of other lung disease including interstitial lung disease (ILD) and bronchiectasis, or history of heart disease including atrial fibrillation and heart failure, or previous lung resection or being a never-smoker. 5008 participants were included for analysis, of whom 2127 (42.5\%) had COPD, 627 had preserved ratio with impaired spirometry (PRISm), and 2254 had normal spirometry. 385 of the COPD patients with $5.5 \pm 0.5$ years of follow-up duration were also assessed at the 10-year visit of COPDGene. The remaining participants had either not yet reached their 10-year visit date or were lost to follow-up.

To identify variables associated the HRR across the whole cohort, we compared HRR characteristics with the reference group of HRR $\leq 5 \mathrm{bt} / \mathrm{min}$ (Table 1). Compared with $\mathrm{HRR} \leq 5 \mathrm{bt} / \mathrm{min}$, individuals with $6 \leq \mathrm{HRR} \leq 10 \mathrm{bt} / \mathrm{min}$ had greater $6 \mathrm{MWD}$, BMI, end-walk $\mathrm{HR}$ and $\mathrm{DL}_{\mathrm{CO}} \%$ pred and slightly lower $\mathrm{Pi}_{10}$ from quantitative $\mathrm{CT}$ (Table 1). However, spirometry, and most other 6MWT- and CTrelated variables were not statistically different between the first 2 quintiles of HRR (Table 1). 


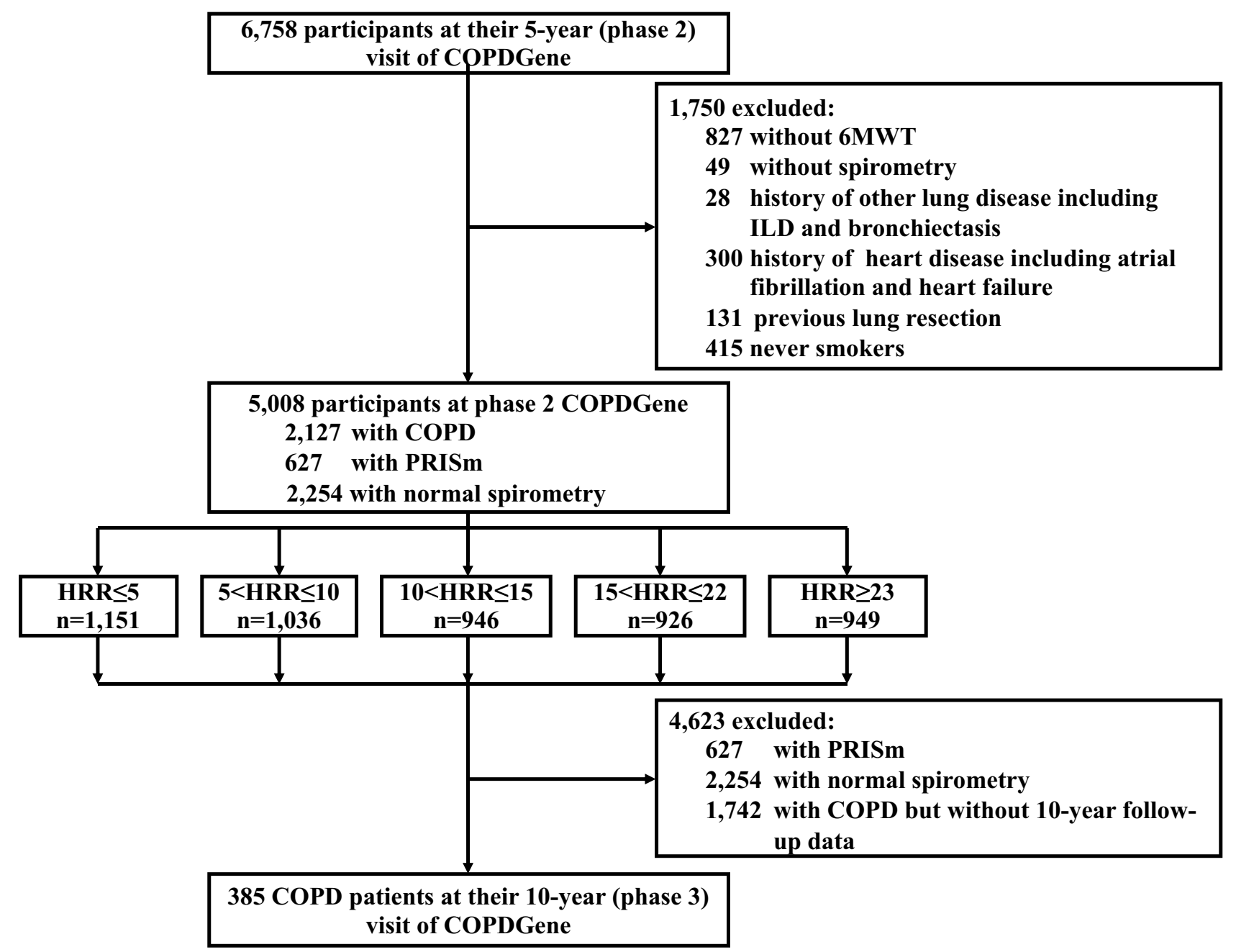

Figure I Study design.

Abbreviation: PRISm, Preserved Ratio Impaired Spirometry defined as $\mathrm{FEV}_{\mathrm{I}} / \mathrm{FVC} \geq 70 \%$ but $\mathrm{FEV},<80 \%$.

However, participants in the 3rd quintile $(11 \leq \mathrm{HRR} \leq 15$ $\mathrm{bt} / \mathrm{min}$ ) had many variables that were significantly different from reference (HRR $\leq 5 \mathrm{bt} / \mathrm{min})$. Those with $H R R \geq 11$ $\mathrm{bt} / \mathrm{min}$ were older, with greater BMI and $6 \mathrm{MWD}$, lower pre-walk HR and 1-min post $\mathrm{HR}$, greater end-walk $\mathrm{HR}$ and $\mathrm{SpO}_{2}$, less impaired spirometry ( $\mathrm{FEV}_{1} \%$ pred, $\mathrm{FEV}_{1} / \mathrm{FVC}$ ), greater $\mathrm{D}_{\mathrm{LCO}} \%$ pred, less gas trapping, Pi10 and airway wall thickness. Therefore, 6MWT, spirometry and CT variables were significantly less impaired in participants at $\mathrm{HRR} \geq 11 \mathrm{bt} / \mathrm{min}$ compared with those in the first two quintiles. Above this quintile, there were few additional significant findings: greater pack-years smoking, greater pre-walk and end-walk $\mathrm{SpO}_{2}$, greater $\mathrm{FVC} \%$ pred and lower airway wall thickness (at $\mathrm{HRR} \geq 16 \mathrm{bt} / \mathrm{min}$ ), and less emphysema (at $H R R \geq 23 \mathrm{bt} / \mathrm{min}$ ). In ROC analysis, an optimal $H R R \leq 10$ beat $/$ min yielded an area under the curve (AUC) of 0.62 (95\% CI 0.58-0.66) for identifying
$\mathrm{FEV}_{1}<30 \%$ pred. This cut-off corresponded to a sensitivity of $62 \%$ and specificity of $58 \%$. Overall, in smokers with and without COPD, HRR $\geq 11 \mathrm{bt} / \mathrm{min}$ was the lowest HRR associated with consistently less impairment in 6MWT, spirometry and CT variables.

\section{Spirometry, Chest CT and HRR}

Associations between measures of pulmonary function and HRR in the whole cohort were further assessed by multivariable generalized linear regression models, adjusted for age, sex, race, BMI, smoking status and cardiovascular disease history. When modelled as a continuous variable, HRR was independently associated with spirometry (Table 2 ). In categorical analyses, compared with $\mathrm{HRR} \leq 5 \mathrm{bt} / \mathrm{min}$, pulmonary function variables $\left(\mathrm{FEV}_{1} \%\right.$ pred, $\mathrm{FVC} \%$ pred, $\mathrm{FEV}_{1}$ $/ \mathrm{FVC}$ and $\mathrm{D}_{\mathrm{LCO}} \%$ pred) were greater (each $\mathrm{P}<0.001$ ) when 


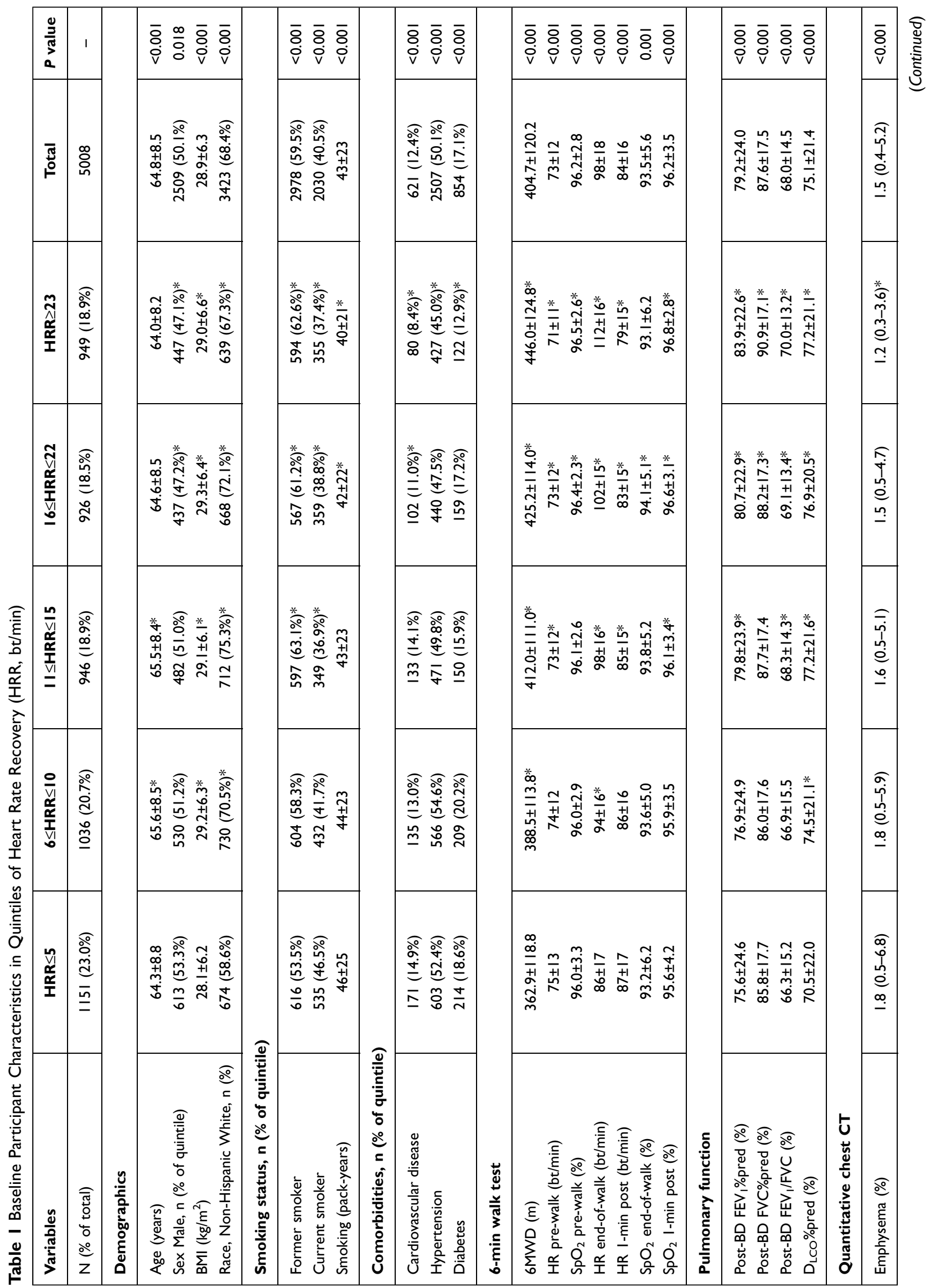



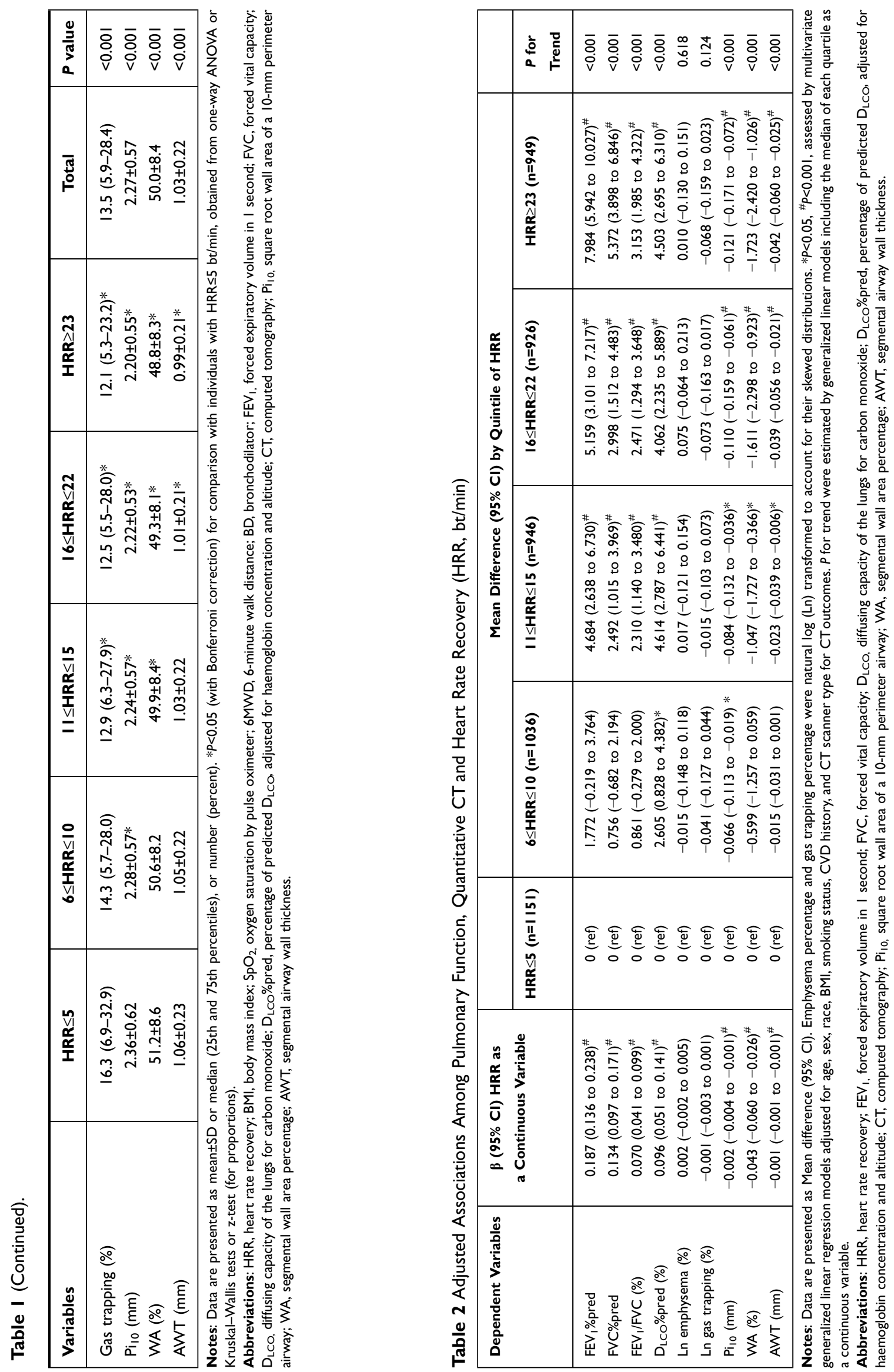
$\mathrm{HRR} \geq 11 \mathrm{bt} / \mathrm{min}$, and increased progressively across $\mathrm{HRR}$ quintiles above this level (each $\mathrm{P}$ for trend $<0.001$ ) (Table 2).

To identify the locus of these associations we performed a sub-group analysis of HRR in COPD, PRISm and normal spirometry. We found that the associations were driven largely by the COPD group, because there were no consistent associations between HRR quintiles and pulmonary function variables in PRISm and normal spirometry groups, assessed separately (Table 3). Only FVC $\%$ pred was weakly associated $(\beta=0.043,95 \% \mathrm{CI}=$ 0.008 to 0.079 ) with HRR as a continuous variable in normal spirometry smokers. In the COPD sub-group, however, all pulmonary function variables were significantly associated with HRR considered as a continuous variable, or as a trend across quintiles $(\mathrm{P}<0.05)$ (Table 3$)$.

We also aimed to explore associations between pulmonary morphology measured by quantitative CT, and HRR in the whole cohort. Multivariable generalized linear regression models were adjusted for age, sex, race, BMI, smoking status, cardiovascular disease history, and CT scanner type. Using HRR as a continuous variable, HRR was independently negatively associated with wall area percentage, airway wall thickness and $\mathrm{Pi}_{10}$ (each $\mathrm{P}<0.001$ ) but not with emphysema or gas trapping (Table 2). This association was also observed in categorical analyses, with wall area percentage, airway wall thickness and $\mathrm{Pi}_{10}$ being consistently less impaired at $H R R \geq 11 \mathrm{bt} / \mathrm{min}$ compared with reference (HRR $\leq 5 \mathrm{bt} /$ min; each $\mathrm{P}<0.05$; Table 2). There was progressive decrease in wall area percentage, airway wall thickness and $\mathrm{Pi}_{10}$ with increase in HRR quintile (each $\mathrm{P}$ for trend $<0.001$ ), but not with emphysema or gas trapping (each $\mathrm{P}$ for trend $>0.124$; Table 2). These findings were again corroborated in subgroup analysis (Table 3) where, in COPD patients, wall area percentage, airway wall thickness and $\mathrm{Pi}_{10}$, but not emphysema or gas trapping, were associated with HRR when HRR was considered as continuous or as categorical variable with $H R R \geq 6$ bt/ min. Wall area percentage and airway wall thickness were significantly negatively associated with HRR as continuous variable in PRISm subjects, however these associations were extremely weak $(\beta<-0.022$; Table 3$)$.

\section{COPD Symptoms, Severity and HRR}

Finding significant associations between HRR and anatomic and functional variables in the COPD sub-group, we then assessed associations with COPD symptoms. Multivariable logistic regression models were adjusted for age, sex, race, BMI, smoking status and cardiovascular disease history. When HRR was modelled as a continuous variable, HRR was independently associated with severe symptoms and exacerbation frequency $\geq 2$ (Table 4 ). In categorical analyses, compared with $\mathrm{HRR} \leq 5 \mathrm{bt} / \mathrm{min}$, odds ratios (ORs) of severe symptoms were decreased (each $\mathrm{P}<0.05$ ) when $H R R \geq 11 \mathrm{bt} / \mathrm{min}$, and decreased progressively across HRR quintiles above this level (each $\mathrm{P}$ for trend $<0.001$ ) (Table 4).

In univariable and multivariable analyses, significant differences among 6MWT, pulmonary function and CT variables in COPD patients were first observed at $H R R \geq 11 \mathrm{bt} / \mathrm{min}$. We therefore explored the association between $H R R \leq 10 \mathrm{bt} / \mathrm{min}$ and COPD severity. After adjusting for age, sex, race, BMI, smoking status and cardiovascular disease history, $H R R \leq 10 \mathrm{bt} / \mathrm{min}$ was independently associated $(\mathrm{P}<0.001)$ with: Exacerbation frequency $\geq 2$ in the previous year $(\mathrm{OR}=1.76[1.33$ $2.34]) ; \mathrm{CAT} \geq 10(\mathrm{OR}=1.42[1.18-1.71]) ;$ and $\mathrm{mMRC} \geq 2$ $(\mathrm{OR}=1.42[1.19-1.69])$ (Figure 2A). Compared to those with $\mathrm{HRR} \geq 11 \mathrm{bt} / \mathrm{min}$, COPD patients with $\mathrm{HRR} \leq 10 \mathrm{bt} /$ min had 1.97 times the risk of very severe obstruction (OR for GOLD $4=1.98[1.44-2.73]$ ) and 1.51 times the risk of having worse symptoms combined with $\geq 2$ exacerbations in the previous year (OR for GOLD $\mathrm{D}=1.51[1.18-1.95]$ ) (Figure 2B).

\section{HRR Predicts Exacerbations at 5-Years}

We then assessed the prognostic value of HRR $10 \leq \mathrm{bt} / \mathrm{min}$ for future exacerbations. Logistic regression models assessed association between $\mathrm{HRR} \leq 10 \mathrm{bt} / \mathrm{min}$ and exacerbations in the year preceding the phase 3 visit in 385 COPD patients. Risk ratios (RR) of future exacerbations predicted by abnormal HRR are presented in Table 5. RR was essentially constant in the crude model, and across 5 models adjusting for a range of variables (Table 5). After adjusting for sex, age, BMI, race, smoking status, cardiovascular disease history, $\mathrm{FEV}_{1} \%$ pred, $\mathrm{D}_{\mathrm{LCO}} \%$ pred and $6 \mathrm{MWD}, \mathrm{HRR} \leq 10 \mathrm{bt} / \mathrm{min}$ was associated with exacerbations risk ratio $(\mathrm{RR}=1.83[1.07-3.12], \mathrm{P}=0.027)$ (Table 5).

\section{COPD Characteristics Stratified by HRR} Having identified an optimal cut-off of HRR $\leq 10 \mathrm{bt} / \mathrm{min}$ was associated with airway morphology, disease severity, dyspnoea, quality of life, exacerbation frequency and risk of future exacerbations in COPD, we compared the characteristics of COPD patients at phase $2(n=2127)$ with $\mathrm{HRR} \leq 10 \mathrm{bt} / \mathrm{min}$ and $\geq 11 \mathrm{bt} / \mathrm{min}$. Compared with COPD 


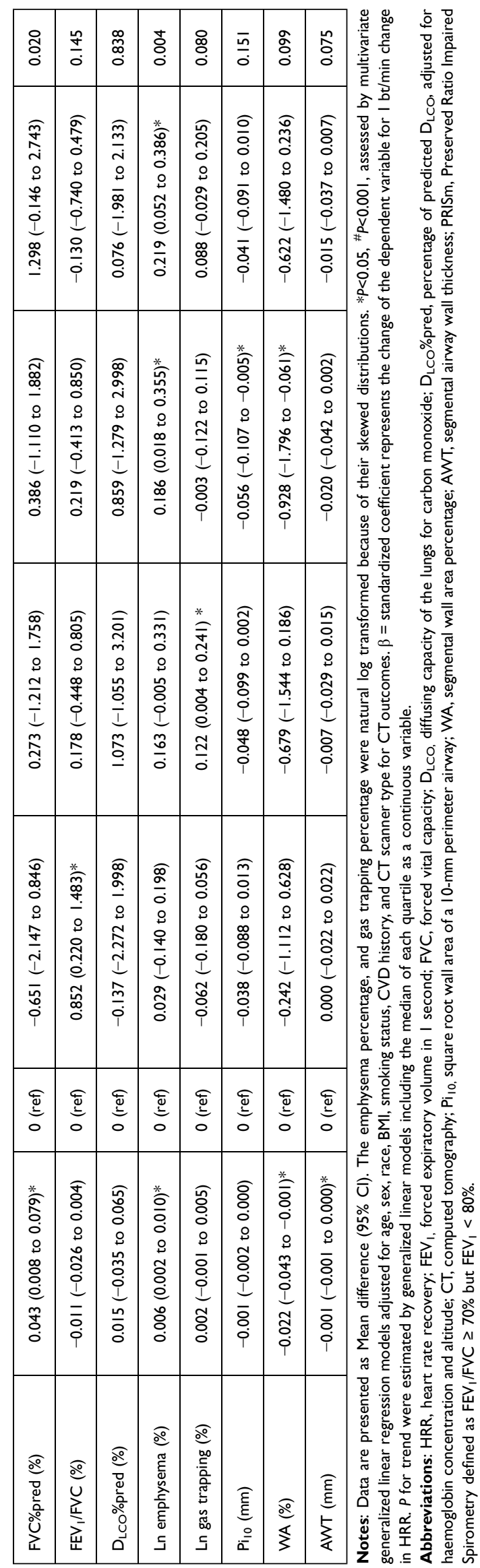

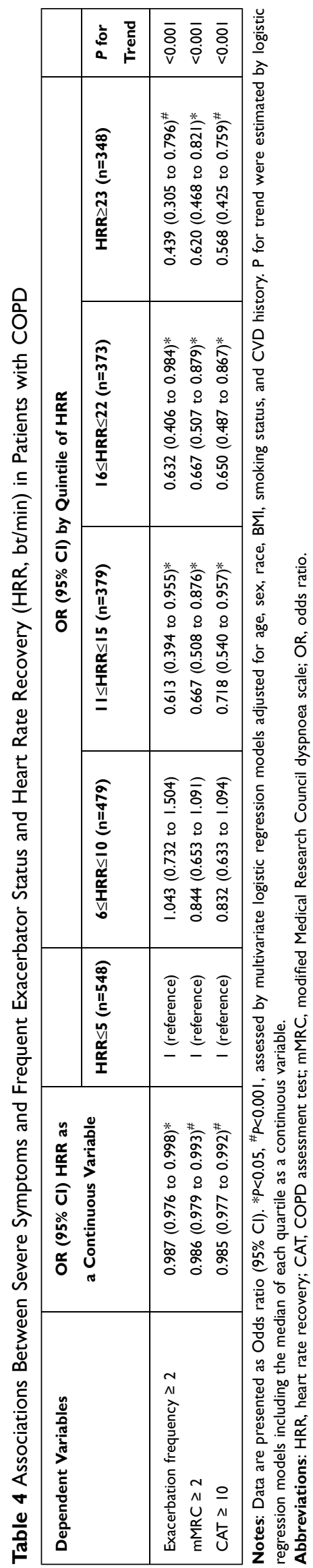




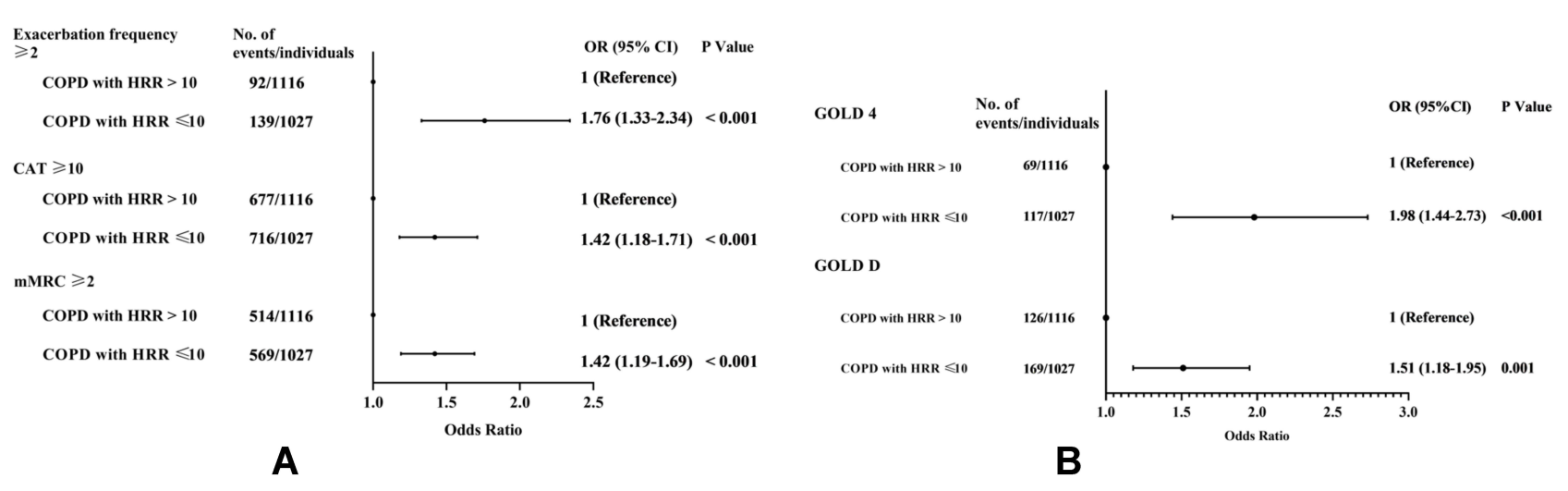

Figure 2 Odds ratio of COPD severity based on abnormal heart rate recovery (HRR $\leq 10 \mathrm{bt} / \mathrm{min}$ ). Multivariable logistic regression model for patients with $\mathrm{COPD}$ ( $\mathrm{n}=2 \mathrm{I} 27$ ) at baseline, adjusting for age, sex, race, BMI and smoking status. (A) Associations between abnormal HRR and severe symptoms. (B) Associations between abnormal HRR and COPD severity grades.

Abbreviations: HRR, heart rate recovery; CAT, COPD assessment test; mMRC, modified Medical Research Council dyspnoea scale; GOLD, Global Initiative for Chronic Obstructive Lung Disease.

patients with $H R R \geq 11 \mathrm{bt} / \mathrm{min}$, those with $\mathrm{HRR} \leq 10 \mathrm{bt} / \mathrm{min}$ had significantly $(\mathrm{P}<0.01)$ : Worse pulmonary function; worse 6MWT physiology (including lower 6MWD, greater pre-walk-HR, lower end-walk-HR, and less recovery of $\mathrm{SpO}_{2}$ ); worse emphysema and airway morphology on chest $\mathrm{CT}$; more severe COPD symptoms; greater exacerbation frequency; and greater combination of inhaled long-acting beta-agonist, inhaled long-acting muscarinic antagonist and inhaled corticosteroid use (Table 6).

\section{Discussion}

This is the first study to show that $H R R \leq 10 \mathrm{bt} / \mathrm{min}$ after 6MWT in COPD patients was an important cut-off which was significantly associated with impaired 6MWT distance, spirometry and $\mathrm{D}_{\mathrm{LCO}}$ and CT variables of airway morphology. This is also the first study to show that low

Table 5 Risk Ratio (RR) for Exacerbations in the Year Prior to 5-Year Follow-Up in 385 Patients with COPD Heart Rate Recovery $(H R R) \leq 10 \mathrm{bt} / \mathrm{min}$ Compared to Those with HRR $\geq \mathrm{I} \mathrm{I} \mathrm{bt} / \mathrm{min}$ (Reference)

\begin{tabular}{|l|c|c|c|}
\hline Variable & RR & 95\% CI & P value \\
\hline Crude & 1.759 & $1.121-2.758$ & 0.014 \\
Model I & 1.747 & $1.111-2.745$ & 0.016 \\
Model 2 & 1.762 & $1.118-2.775$ & 0.015 \\
Model 3 & 1.775 & $1.126-2.798$ & 0.014 \\
Model 4 & 1.823 & $1.148-2.894$ & 0.011 \\
Model 5 & 1.827 & $1.071-3.115$ & 0.027 \\
\hline
\end{tabular}

Notes: Logistic regression model for COPD patients followed-up for 5-years $(n=385)$. Crude: Single factor for logistic regression. Model I: Adjusted for sex. Model 2: Adjusted for sex, age. Model 3: Adjusted for sex, age, body mass index (BMI). Model 4: Adjusted for sex, age, body mass index (BMI), race, smoking status, CVD. Model 5: Adjusted for sex, age, body mass index (BMI), race, smoking status, CVD, FEV $\%$ pred, $D_{\text {LCo }} \%$ pred, 6MWD.
HRR was independently associated with airway wall thickening in smokers with or without COPD, suggesting airway morphologic changes may influence autonomic function. Using $H R R \leq 10 \mathrm{bt} / \mathrm{min}$ cut-off, we showed increased odds in COPD patients of worse dyspnoea and quality of life and increased exacerbation frequency. In addition, in a subgroup of 385 COPD patients, we also showed that $H R R \leq 10 \mathrm{bt} / \mathrm{min}$ was a significant predictor of exacerbations during the year preceding the 5 year followup visit. $H R R \leq 10 \mathrm{bt} / \mathrm{min}$ at 1 -minute after a $6 \mathrm{MWT}$ in COPD is, therefore, proposed as an important tool to evaluate the clinical manifestation of severe outcomes in COPD.

Seshadri et al (2004) were the first to characterize HRR in COPD patients. In 627 participants, they found that $\mathrm{HRR} \leq 12 \mathrm{bt} / \mathrm{min}$ after incremental exercise testing in smokers and non-smokers was associated with spirometric abnormalities, such as lower $\mathrm{FEV}_{1} \%$ pred. ${ }^{8}$ This was corroborated by Gupta et al (2013), who found that COPD patients with $H R R \leq 12 \mathrm{bt} / \mathrm{min}$ after target-HR-limited or symptom-limited incremental cycle ergometry had lower $\mathrm{FEV}_{1} \%$ pred than those with $\mathrm{HRR} \geq 13 \mathrm{bt} / \mathrm{min}$, and that abnormal HRR increased in frequency together with GOLD-defined COPD severity. ${ }^{9}$ Both studies used the HRR $\leq 12 \mathrm{bt} / \mathrm{min}$ criterion established by Cole et al (1999) who - from a prospective cohort referred for exercise testing - showed that this cut-off associated with mortality in cardiovascular disease patients. ${ }^{5}$ It was suggested that autonomic dysfunction (reflected in elevated heart rate, reduced baroreflex sensitivity, reduced heart rate variability and/or prolonged QTc interval) would also result in low HRR following exercise. ${ }^{29}$ However, the 
Table 6 Characteristics of Patients with COPD Stratified by a Criterion Heart Rate Recovery (HRR) After 6MWT of 10 bt/min

\begin{tabular}{|c|c|c|c|c|}
\hline Variables & $\begin{array}{l}\text { COPD with Abnormal HRR } \\
\leq 10 \mathrm{bt} / \mathrm{min}(\mathrm{n}=1027)\end{array}$ & $\begin{array}{l}\text { COPD with Normal HRR } \geq I I \\
b t / \min (n=1100)\end{array}$ & Total $(n=2 \mid 27)$ & $P$ value \\
\hline \multicolumn{5}{|l|}{ Demographics } \\
\hline Age (years) & $67.5 \pm 8.5$ & $67.5 \pm 8.1$ & $67.5 \pm 8.3$ & 0.958 \\
\hline Sex, Male, n (\%) & $570(28.3 \%)$ & $602(26.8 \%)$ & 1172 (55.1\%) & 0.720 \\
\hline BMI $\left(\mathrm{kg} / \mathrm{m}^{2}\right)$ & $27.6 \pm 6.2$ & $28.1 \pm 6.1$ & $27.9 \pm 6.2$ & 0.069 \\
\hline Race, Non-Hispanic White, $n$ (\%) & $743(34.9 \%)$ & 857 (40.3\%) & $1600(75.2 \%)$ & 0.003 \\
\hline \multicolumn{5}{|l|}{ Smoking status, n (\%) } \\
\hline Ex-smoker & $631(29.7 \%)$ & 707 (33.2\%) & 1338 (62.9\%) & 0.177 \\
\hline Current smoker & 396 (18.6\%) & $393(18.5 \%)$ & $789(37.1 \%)$ & 0.177 \\
\hline Smoking (pack-years) & $51 \pm 26$ & $49 \pm 24$ & $50 \pm 25$ & 0.107 \\
\hline \multicolumn{5}{|l|}{ 6-min walk test } \\
\hline 6MWD $(\mathrm{m})$ & $350.3 \pm 118.7$ & $396.6 \pm 122.8$ & $374.3 \pm 123.0$ & $<0.001$ \\
\hline HR pre-walk (bt/min) & $76 \pm 13$ & $73 \pm 12$ & $75 \pm 13$ & $<0.001$ \\
\hline $\mathrm{SpO}_{2}$ pre-walk (\%) & $95.0 \pm 3.7$ & $95.6 \pm 3.1$ & $95.3 \pm 3.4$ & 0.001 \\
\hline HR end-walk (bt/min) & $91 \pm 17$ & $104 \pm 17$ & $98 \pm 18$ & $<0.001$ \\
\hline HR I-min post (bt/min) & $87 \pm 16$ & $83 \pm 15$ & $85 \pm 16$ & $<0.001$ \\
\hline $\mathrm{SpO}_{2}$ end-walk (\%) & $91.9 \pm 6.0$ & $92.1 \pm 6.0$ & $92.0 \pm 6.0$ & 0.531 \\
\hline $\mathrm{SpO}_{2}$ I-min post (\%) & $94.6 \pm 4.6$ & $95.5 \pm 3.9$ & $95.1 \pm 4.2$ & $<0.001$ \\
\hline \multicolumn{5}{|l|}{ Pulmonary function } \\
\hline Post-BD FEV $1 \%$ pred (\%) & $59.7 \pm 22.5$ & $64.1 \pm 22.4$ & $62.0 \pm 22.6$ & $<0.001$ \\
\hline Post-BD FVC\%pred (\%) & $81.9 \pm 19.5$ & $85.4 \pm 19.8$ & $83.7 \pm 19.7$ & $<0.001$ \\
\hline Post-BD FEVI/FVC (\%) & $53.8 \pm 12.7$ & $55.5 \pm 11.7$ & $54.7 \pm 12.3$ & 0.001 \\
\hline D Lco\%pred (\%) & $62.6 \pm 22.1$ & $66.1 \pm 21.5$ & $64.4 \pm 21.9$ & 0.001 \\
\hline \multicolumn{5}{|l|}{ Quantitative chest CT } \\
\hline Emphysema (\%) & $5.9(1.9-16.6)$ & $5.0(1.6-14.5)$ & $5.4(1.7-15.3)$ & 0.008 \\
\hline Gas trapping (\%) & $31.1(18.3-51.5)$ & $29.6(15.8-46.3)$ & $30.4(16.9-49.2)$ & 0.005 \\
\hline $\mathrm{Pi}_{10}(\mathrm{~mm})$ & $2.6 \pm 0.6$ & $2.5 \pm 0.6$ & $2.5 \pm 0.6$ & 0.035 \\
\hline WA (\%) & $53.6 \pm 8.3$ & $52.6 \pm 8.2$ & $53.1 \pm 8.2$ & 0.011 \\
\hline AWT (mm) & $1.11 \pm 0.24$ & $1.07 \pm 0.22$ & $1.09 \pm 0.23$ & 0.001 \\
\hline \multicolumn{5}{|l|}{ COPD assessment } \\
\hline Exacerbations/year & $0(0-1)$ & $0(0-0)$ & $0(0-1)$ & 0.036 \\
\hline Exacerbation frequency $\geq 2, n(\%)$ & $139(6.5 \%)$ & $92(4.3 \%)$ & $231(10.9 \%)$ & $<0.001$ \\
\hline $\mathrm{mMRC}$ & $2(0-3)$ & I (0-3) & $2(0-3)$ & $<0.001$ \\
\hline CAT & $15(8-22)$ & $12(7-19)$ & $13(7-20)$ & $<0.001$ \\
\hline CAT $\geq 10, n(\%)$ & $716(33.7 \%)$ & $677(31.8 \%)$ & $1393(65.5 \%)$ & $<0.001$ \\
\hline mMRC $\geq 2, \mathrm{n}(\%)$ & $569(26.8 \%)$ & $514(24.2 \%)$ & $1083(50.9 \%)$ & $<0.001$ \\
\hline \multicolumn{5}{|l|}{ Medication, n (\%) } \\
\hline Non-medication & $336(15.8 \%)$ & $453(21.3 \%)$ & $789(37.1 \%)$ & $<0.001$ \\
\hline LABA use & II (0.5\%) & $8(0.4 \%)$ & $19(0.9 \%)$ & 0.400 \\
\hline LAMA use & $99(4.7 \%)$ & $88(4.1 \%)$ & I 87 (8.8\%) & 0.182 \\
\hline LABA+LAMA use & $18(0.8 \%)$ & $20(0.9 \%)$ & $38(1.8 \%)$ & 0.909 \\
\hline ICS+LABA or LAMA use & $168(7.9 \%)$ & $164(7.7 \%)$ & $332(15.6 \%)$ & 0.357 \\
\hline LABA+LAMA+ ICS use & 206 (9.7\%) & 177 (8.3\%) & $383(18.0 \%)$ & 0.017 \\
\hline Others & 189 (8.9\%) & 190 (8.9\%) & $379(17.8 \%)$ & 0.496 \\
\hline
\end{tabular}

Note: Data are presented as mean \pm SD or median (interquartile range), or number (percent).

Abbreviations: $\mathrm{HRR}$, heart rate recovery; $\mathrm{BMI}$, body mass index; $\mathrm{SpO}_{2}$, oxygen saturation by pulse oximeter; 6MWD, 6-minute-walk distance; $\mathrm{BD}$, bronchodilator; $\mathrm{FEV}$, forced expiratory volume in I second; FVC, forced vital capacity; $D_{L C O}$, diffusing capacity of the lungs for carbon monoxide; $D_{L C O} \%$ pred, percentage of predicted $D_{L C O}$, adjusted for haemoglobin concentration and altitude; CT, computed tomography; Pil0, square root wall area of a 10-mm perimeter airway; WA\%, segmental wall area percentage; AWT, segmental airway wall thickness; CAT, COPD assessment test; mMRC, modified Medical Research Council dyspnoea scale; GOLD, Global Initiative for Chronic Obstructive Lung Disease; LABA, inhaled long-acting beta-agonist; LAMA, inhaled long-acting muscarinic antagonist; ICS, inhaled corticosteroid. 
HRR $\leq 12 \mathrm{bt} / \mathrm{min}$ criterion value may not be suitable after 6MWT in COPD patients, who commonly reach symptom limitation before reaching cardiovascular limitation during exercise. ${ }^{30}$ Lower peak HR during exercise would predispose towards smaller HRR. Indeed, our data show in COPD patients stratified on HRR $\leq 10 \mathrm{bt} / \mathrm{min}$ (Table 6), that pre-walk HR is significantly higher (by $3 \mathrm{bt} / \mathrm{min}$ ) and end-walk HR is significantly lower (by $15 \mathrm{bt} / \mathrm{min}$ ) than those with $H R R \geq 11 \mathrm{bt} / \mathrm{min}$. These patients also had worse spirometry, $\mathrm{D}_{\mathrm{LCO}}$, airway wall thickening and symptom and exacerbation burden. This is consistent with the notion that more severe COPD patients are less able to increase HR during 6MWT and, therefore, less able to recover by $\geq 11 \mathrm{bt} / \mathrm{min}$. We suggest that $H R R \leq 10 \mathrm{bt} / \mathrm{min}$ can be used to identify COPD patients at greater risk for worse dyspnoea, quality of life and future exacerbations.

COPD is characterized by poorly-reversible expiratory airflow limitation, caused by emphysema and/or airway remodeling. ${ }^{31,32}$ Airway wall thickening and emphysema provide independent contributions to expiratory flow limitation and gas exchange impairment in COPD. ${ }^{26}$ Lower $\mathrm{FEV}_{1}$ is associated with both greater airway wall thickness $^{33,34}$ and with emphysema and gas trapping. ${ }^{35,36}$ We used $\mathrm{CT}$ to assess airway remodeling ${ }^{33}$ and emphysema $^{37}$ in relation to 6MWT performance and HRR. We measured wall area percentage, airway wall thickness and $\mathrm{Pi}_{10}$, which collectively reflect wall thickening across the entire bronchial tree and negatively associate with $\mathrm{FEV}_{1}{ }^{35}$ We demonstrated that wall area percentage, airway wall thickness and $\mathrm{Pi}_{10}$, but not measures of emphysema, decreased progressively with increasing HRR, and were independently negatively associated with $H R R \leq 10 \mathrm{bt} / \mathrm{min}$ in smokers with or without COPD. As emphysema and impaired $\mathrm{D}_{\mathrm{LCO}}$ are more strongly associated with exercise-induced arterial hypoxemia, it might be hypothesized that HRR recovery would be more impaired in those with greater gas exchange abnormalities. ${ }^{38}$ In accordance with this suggestion, $\mathrm{D}_{\text {LCO }}$ was negatively associated with HRR, but we found no relation between HRR and emphysema on CT. In addition, although 1515 (30.3\%) participants experienced at least mild exercise induced arterial desaturation $\left(\mathrm{SpO}_{2}\right.$ $<92 \%$ ), this was only very weakly associated with HRR $\left(\beta=0.016,95 \%\right.$ CI $\left.0.005-0.027, \mathrm{r}^{2}=0.002\right)$ (c.f. $\left.{ }^{39}\right)$. Our results are therefore consistent with a greater autonomic disturbance in airway predominant disease rather than in emphysema.
Vagal afferent innervation of the respiratory tract is thought to be activated in COPD by alterations in airway mechanical stimuli, inflammatory and noxious sensory stimuli, ${ }^{16,17}$ increasing bronchoconstriction and susceptibility to cough. Similarly, sympathetic activity is enhanced in COPD patients, and is known to be affected by several mechanisms associated with COPD, including: Recurrent hypoxemia; hypercapnia; increased intrathoracic pressure alterations; respiratory effort; systemic inflammation; pulmonary circulation; and use of beta-sympathomimetics resulting in augmented cardiac afterload. Indeed, anticholinergic bronchodilators reduce HRR after exercise in COPD patients, ${ }^{40}$ and we found greater combination of LABA, LAMA and inhaled corticosteroids use in those with abnormal HRR. However, although patients did not temporarily abstain from long-acting bronchodilator medications for this study, the 6MWT was conducted after albuterol administration for spirometry assessment in all participants, meaning beta-agonist load should have been high in all subjects. In addition, chronic inflammation is associated with autonomic dysfunction in middle-aged and elderly subjects with no apparent heart disease. ${ }^{41}$ Taken together, our findings support that chronic inflammation and/or an association between bronchial and cardiac vagal tone are reflected in an association between airway wall thickness and abnormal HRR in COPD patients. Therefore, HRR $\leq 10 \mathrm{bt} / \mathrm{min}$ cut-off might provide a prognostic feature of airway-dominant COPD. ${ }^{42}$ Further study is warranted to identify mechanisms involved in associations among HRR, parasympathetic nervous activity and airway wall thickness in COPD. Indeed, the association between HRR and airway abnormalities remains even when diagnostic criteria (eg COPD or non-COPD) are considered. This suggests that HRR may represent a treatable trait, ${ }^{43}$ mediated by an underlying airway and/or autonomic pathophysiology, that could be a target to improve outcomes agnostic of diagnostic phenotype.

The GOLD ABCD assessment tool ${ }^{20,44}$ identifies highest risk COPD patients using exacerbation frequency $\geq 2$ in the previous year, combined with significant dyspnoea assessed by CAT $\geq 10$ or $\mathrm{mMRC} \geq 2$. GOLD D patients have the worst health status and outcomes. ${ }^{20}$ To our knowledge, this is the first study to show that HRR $\leq 10$ $\mathrm{bt} / \mathrm{min}$ was independently associated with GOLD D COPD classification. COPD patients with $H R R \leq 10 \mathrm{bt} / \mathrm{min}$ have greater risk for symptoms and frequent exacerbations than those with $H R R \geq 11 \mathrm{bt} / \mathrm{min}$. We also demonstrated that $\mathrm{HRR} \leq 10 \mathrm{bt} / \mathrm{min}$ was a predictor for future exacerbation at 5-year follow-up in 385 COPD patients. 
Previous studies have associated $\mathrm{HRR} \leq 14 \mathrm{bt} / \mathrm{min}$ with future exacerbation risk ${ }^{15}$ or mortality in COPD. ${ }^{7}$ These studies, however, found no association between HRR and pulmonary function or symptoms. HRR $\leq 10 \mathrm{bt} / \mathrm{min}$ after 6MWT, on the other hand, identified associations with both COPD severity and future exacerbation. This, again, supports the notion that $H R R \leq 10 \mathrm{bt} / \mathrm{min}$ after $6 \mathrm{MWT}$ may further inform COPD prognosis.

Our study has several limitations. Firstly, we do not have mortality data to assess association with HRR at different cut-off values. At the time of writing, only a modest fraction of COPDGene participants have been followed up at their 10-year visit (phase 3), introducing potential for selection bias in our exacerbation outcome data. There also remains chance bias due to the multiple outcomes examined. Secondly, common medications such as $\beta$-agonists may alter the HR and HRR response to 6MWT. However, the type and amount of medication use is a Co-variate of COPD severity; therefore, adjusting for medication confounds analyses for associations between HRR and COPD severity. We also sought to adjust for peak HR in our models. Adjustment of peak HR tended to increase the strength of association between HRR and some model variables, eg the association between $\mathrm{HRR}$ and $\mathrm{FEV}_{1} \%$ pred increased from $\beta=0.194$ to $\beta=0.318 \quad(\mathrm{P}<0.001$ for both). However, peak HR is used in the calculation of HRR, and its inclusion introduced variance of the coefficients without major impact on the primary study conclusions. For this reason, peak HR was not included in the presented models. In addition, exacerbations in the previous year are known to be the primary predictor of subsequent exacerbations. Since we did not measure exacerbations prior to our follow-up window, we are not able to assess the independence of HRR as a predictor of exacerbations at 5-year follow up. Finally, patients with $H R R \leq 10 \mathrm{bt} / \mathrm{min}$ are also included in groups with greater cut-off values (eg, $\leq 12-16 \mathrm{bt} / \mathrm{min}$ ), which introduces bias when attempting to identify which cut-off value to use. Here we chose to report the lowest value, because COPD is predisposed to lower end-walk HR values than some other patient populations. Although not shown, using $\leq 12, \leq 14$ or $\leq 16 \mathrm{bt} / \mathrm{min}$ as more granular criteria cutoff values, did not change the main finding that HRR $\leq 10 \mathrm{bt} / \mathrm{min}$ was the lowest HRR criterion identifying severe impairments in clinical outcomes.

\section{Conclusions}

In conclusion, in this retrospective study we demonstrated that $\mathrm{HRR} \leq 10 \mathrm{bt} / \mathrm{min}$ after 6MWT in COPD was associated with: 1) worse lung function and airway wall thickening; 2) worse dyspnoea and quality of life; and 3) greater exacerbation burden; and was 4) prognostic of future exacerbations. These findings suggest that HRR of $\leq 10 \mathrm{bt} / \mathrm{min}$ may be useful as part of a comprehensive longitudinal assessment in COPD patients to determine risk for disease severity, symptoms and future exacerbations.

\section{Abbreviations}

6MWT, Six-minute walk test; 6MWD, Six-minute walk distance; ATS, American Thoracic Society; AWT, Airway wall thickness; BD, Bronchodilator; BMI, Body mass index; CAT, COPD assessment test; CT, Computed tomography; COPD, Chronic obstructive pulmonary disease; PRISm, Preserved Ratio Impaired Spirometry $\left(\mathrm{FEV}_{1} / \mathrm{FVC} \geq 70 \%\right.$ and $\mathrm{FEV}_{1}<80 \%$ ); CVD, Cardiovascular disease; CPET, Cardiopulmonary exercise test; $\mathrm{FEV}_{1}$, Forced expiratory volume in one second; $\mathrm{FEV}_{1} \%$ pred, Percentage of predicted $\mathrm{FEV}_{1}$; FVC, Forced vital capacity; FVC\%pred, Percentage of predicted FVC; $\mathrm{D}_{\mathrm{LCO}}$, Diffusing capacity of the lungs for carbon monoxide; $\mathrm{D}_{\mathrm{LCO}} \%$ pred, Percentage of predicted $\mathrm{D}_{\mathrm{LCO}}$, adjusted for haemoglobin concentration and altitude; GOLD, Global Initiative for Chronic Obstructive Lung Disease; HRR, Heart rate recovery; HRV, Heart rate variability; HU, Hounsfield units; ICS, Inhaled corticosteroids; ILD, Interstitial lung disease; LABA, Inhaled long-acting beta-agonist; LAMA, Inhaled long-acting muscarinic antagonist; mMRC, modified Medical Research Council dyspnoea questionnaire; $\mathrm{Pi}_{10}$, Square root of the wall area of a $10-\mathrm{mm}$ perimeter airway; WA $\%$, Wall area percentages.

\section{Declaration}

Notation of prior abstract publication/presentation: Results of this study have been presented at the European Respiratory Society VIRTUAL CONGRESS 2020.

\section{Guarantor Statement}

Harry B. Rossiter is the guarantor of the content of the manuscript, including the data and analysis.

\section{Role of the Sponsors}

The sponsor had no role in the design of the study, the collection and analysis of the data, or the preparation of the manuscript. 


\section{Data Sharing Statement}

The datasets used and analysed during the current study are available from the COPDGene study on reasonable request.

\section{Ethics Approval and Consent to Participate}

The clinical study was approved by the Institutional Review Boards of each centre participating in the COPDGene study (NCT00608764). Informed consent about the study procedures was signed and obtained from all the subjects before participation.

\section{Acknowledgments}

Other contributions: The authors would like to thank the COPDGene study participants and all investigators at the investigative sites from the COPDGene study for their support of this study.

\section{Author Contributions}

All authors made a significant contribution to the work reported, whether that is in the conception, study design, execution, acquisition of data, analysis and interpretation, or in all these areas; took part in drafting, revising or critically reviewing the article; gave final approval of the version to be published; have agreed on the journal to which the article has been submitted; and agree to be accountable for all aspects of the work.

\section{Funding}

The COPDGene study is supported by grants from the National Heart, Lung, and Blood Institute (NIH/NHLBI R01HL089897, R01HL089856 [(Rossiter, Adami], U01HL089897, U01HL089856 [(Crapo, Silverman; COPDGene]).

\section{Disclosure}

Summary conflict of interest statements: The authors report funding from the NIH in direct support of this work; other support, including consultancy, advisory board fees and contracted research from industry is outside the submitted work. A full list of disclosures is provided.

Dongxing Zhao has no disclosures to report.

Asghar Abbasi is supported by a postdoctoral fellowship from the Tobacco-Related Disease Research Program (28FT-0017).
Richard Casaburi reports personal fees from Glaxo Smith Kline, Boehringer Ingelheim, Astra Zeneca, Regeneron and Genentech and contracted clinical research support from Astra Zeneca, Boehringer Ingelheim, Glaxo Smith Kline, Genentech and Regeneron outside the submitted work.

Alessandra Adami is supported by a grant from NIH/ NHLBI (R01HL151452).

Nicholas B. Tiller is supported by a postdoctoral fellowship from the Tobacco-Related Disease Research Program (T31FT1692).

Wei Yuan has no disclosures to report.

Christopher Yee has no disclosures to report.

Nicholas Jendzjowsky reports grant funding from AazeinTx, outside the submitted work; is a Parker B Francis Fellowship Recipient; reports US provisional patent, application no. 59263173-179 outside the submitted work; has patent $62 / 534,638$ pending to University of Calgary.

David MacDonald has no disclosures to report.

Ken Kunisaki reports grants from NIH, during the conduct of the study, personal fees from Nuvaira for data safety and monitoring board services, and contracted clinical research support from Sanofi outside the submitted work.

William Stringer reports research funding from AstraZeneca and consultancy for GlaxoSmithKline outside the submitted work.

Janos Porszasz reports contracted clinical research support with United Therapeutics, Genentech and Regeneron outside the submitted work.

Barry Make reports (related to the general topic of COPD over the last three years) grants from NHLBI, Pearl Research, Circassia, GlaxoSmithKline and AstraZeneca; advisory board fees from GlaxoSmithKline, AstraZeneca, Boehringer Ingelheim, Verona, Third Pole, and Phillips; consulting fees from AstraZeneca; medical board member, grants, non-financial support, grant funds provided to and controlled by National Jewish Health for/ from Astra Zeneca, grants and CME activity for/from Glaxo Smith Kline, CME activity for Wolters Kluwer Health, Spiration, CME activity for Sunovion, Mt Sinai, Web MD, National Jewish Health, Novartis, American College of Chest Physicians, Projects in Knowledge, Hybrid Communications, Medscape, Ultimate Medical Academy, Eastern Pulmonary Society, Catamount Medical, Eastern VA Medical Center, and Academy Continued Health Care Learning, grants from Pearl 
Research (funds provided to and controlled by National Jewish Health), medical advisory board for Verona, Boehringer Ingelheim, Theravance, Phillips, and Science 24/7, non-financial support from Circassia, personal fees from Third Pole and Takeda, and grants from NHLBI, outside the submitted work.

Russ Bowler has no disclosures to report.

Harry Rossiter is supported by grants from NIH (R01HL151452, P50HD098593， R01DK122767, P2CHD086851) and the Tobacco Related Disease Research Program (T31IP1666). He reports consulting fees from Omniox Inc., and is involved in contracted clinical research with Boehringer Ingelheim, GlaxoSmithKline, Novartis, AstraZeneca, Astellas, United Therapeutics, Genentech and Regeneron.

The authors report no other potential conflicts of interest for this work.

\section{References}

1. Stewart AG, Waterhouse JC, Howard P. Cardiovascular autonomic nerve function in patients with hypoxaemic chronic obstructive pulmonary disease. Eur Respir J. 1991;4(10):1207-1214.

2. Stewart AG, Marsh F, Waterhouse JC, Howard P. Autonomic nerve dysfunction in COPD as assessed by the acetylcholine sweat-spot test. Eur Respir J. 1994;7(6):1090-1095.

3. La Rovere MT, Bigger JT Jr, Marcus FI, Mortara A, Schwartz PJ. Baroreflex sensitivity and heart-rate variability in prediction of total cardiac mortality after myocardial infarction. ATRAMI (Autonomic Tone and Reflexes After Myocardial Infarction) Investigators. Lancet. 1998;351(9101):478-484. doi:10.1016/S0140-6736(97)11144-8

4. Tsuji H, Venditti FJ Jr, Manders ES, et al. Reduced heart rate variability and mortality risk in an elderly cohort. The Framingham Heart Study. Circulation. 1994;90(2):878-883. doi:10.1161/01. CIR.90.2.878

5. Cole CR, Blackstone EH, Pashkow FJ, Snader CE, Lauer MS. Heartrate recovery immediately after exercise as a predictor of mortality. $N$ Engl J Med. 1999;341(18):1351-1357. doi:10.1056/NEJM199 910283411804

6. Cole CR, Foody JM, Blackstone EH, Lauer MS. Heart rate recovery after submaximal exercise testing as a predictor of mortality in a cardiovascularly healthy cohort. Ann Intern Med. 2000;132 (7):552-555. doi:10.7326/0003-4819-132-7-200004040-00007

7. Lacasse M, Maltais F, Poirier P, et al. Post-exercise heart rate recovery and mortality in chronic obstructive pulmonary disease. Respir Med. 2005;99(7):877-886. doi:10.1016/j.rmed.2004.11.012

8. Seshadri N, Gildea TR, McCarthy K, Pothier C, Kavuru MS, Lauer MS. Association of an abnormal exercise heart rate recovery with pulmonary function abnormalities. Chest. 2004;125 (4):1286-1291. doi:10.1378/chest.125.4.1286

9. Gupta M, Bansal V, Chhabra SK. Abnormal heart rate recovery and chronotropic incompetence on exercise in chronic obstructive pulmonary disease. Chron Respir Dis. 2013;10(3):117-126. doi:10.1177/ 1479972313493097

10. Celli B, Tetzlaff K, Criner G, et al. The 6-Minute-Walk Distance Test as a Chronic Obstructive Pulmonary Disease Stratification Tool. Insights from the COPD Biomarker Qualification Consortium. Am J Respir Crit Care Med. 2016;194(12):1483-1493. doi:10.1164/ rccm.201508-16530C
11. Cahalin LP, Arena R, Labate V, Bandera F, Lavie CJ, Guazzi M. Heart rate recovery after the 6 min walk test rather than distance ambulated is a powerful prognostic indicator in heart failure with reduced and preserved ejection fraction: a comparison with cardiopulmonary exercise testing. Eur J Heart Fail. 2013;15(5):519-527. doi:10.1093/eurjhf/hfs216

12. Swigris JJ, Swick J, Wamboldt FS, et al. Heart rate recovery after 6-min walk test predicts survival in patients with idiopathic pulmonary fibrosis. Chest. 2009;136(3):841-848. doi:10.1378/chest.09-0211

13. Groepenhoff H, Vonk-Noordegraaf A, van de Veerdonk MC, Boonstra A, Westerhof N, Bogaard HJ. Prognostic relevance of changes in exercise test variables in pulmonary arterial hypertension. PLoS One. 2013;8(9):e72013. doi:10.1371/journal. pone.0072013

14. Minai OA, Nguyen Q, Mummadi S, Walker E, McCarthy K, Dweik RA. Heart rate recovery is an important predictor of outcomes in patients with connective tissue disease-associated pulmonary hypertension. Pulm Circ. 2015;5(3):565-576. doi:10.1086/682432

15. Rodríguez DA, Kortianou EA, Alison JA, et al. Heart Rate Recovery After 6-min Walking Test Predicts Acute Exacerbation in COPD. Lung. 2017;195(4):463-467. doi:10.1007/s00408-017-0027-0

16. Mazzone SB, Undem BJ. Vagal Afferent Innervation of the Airways in Health and Disease. Physiol Rev. 2016;96(3):975-1024. doi:10.1152/physrev.00039.2015

17. Belvisi MG, Birrell MA, Khalid S, et al. Neurophenotypes in Airway Diseases. Insights from Translational Cough Studies. Am J Respir Crit Care Med. 2016;193(12):1364-1372. doi:10.1164/rccm.201508$1602 \mathrm{OC}$

18. Regan EA, Hokanson JE, Murphy JR, et al. Genetic epidemiology of COPD (COPDGene) study design. Copd. 2010;7(1):32-43. doi:10.3109/15412550903499522

19. ATS Committee on Proficiency Standards for Clinical Pulmonary Function Laboratories. ATS statement: guidelines for the six-minute walk test. Am J Respir Crit Care Med. 2002;166(1):111-117. doi:10.1164/ajrccm.166.1.at1102

20. GOLD Science Committee. Global Strategy for the Diagnosis, Management and Prevention of Chronic Obstructive Lung Disease 2020 Report. Global Initiative for Chronic Obstructive Lung Disease (GOLD). Available from: http://www.goldcopd.org. Accessed August 23, 2021.

21. Hurst JR, Vestbo J, Anzueto A, et al. Susceptibility to exacerbation in chronic obstructive pulmonary disease. $N$ Engl J Med. 2010;363 (12):1128-1138. doi:10.1056/NEJMoa0909883

22. Miller MR, Hankinson J, Brusasco V, et al. Standardisation of spirometry. Eur Respir J. 2005;26(2):319-338. doi:10.1183/ 09031936.05 .00034805

23. Macintyre N, Crapo RO, Viegi G, et al. Standardisation of the single-breath determination of carbon monoxide uptake in the lung. Eur Respir J. 2005;26(4):720-735. doi:10.1183/09031936.0 5.00034905

24. Miller A, Thornton JC, Warshaw R, Anderson H, Teirstein AS, Selikoff IJ. Single breath diffusing capacity in a representative sample of the population of Michigan, a large industrial state. Predicted values, lower limits of normal, and frequencies of abnormality by smoking history. Am Rev Respir Dis. 1983;127(3):270-277.

25. Nakano Y, Wong JC, de Jong PA, et al. The prediction of small airway dimensions using computed tomography. Am J Respir Crit Care Med. 2005;171(2):142-146. doi:10.1164/rccm.200407-874OC

26. Patel BD, Coxson HO, Pillai SG, et al. Airway wall thickening and emphysema show independent familial aggregation in chronic obstructive pulmonary disease. Am J Respir Crit Care Med. 2008;178(5):500-505. doi:10.1164/rccm.200801-059OC

27. Martinez CH, Chen YH, Westgate PM, et al. Relationship between quantitative CT metrics and health status and BODE in chronic obstructive pulmonary disease. Thorax. 2012;67(5):399-406. doi:10.1136/thoraxjnl-2011-201185 
28. Barr RG, Berkowitz EA, Bigazzi F, et al. A combined pulmonary-radiology workshop for visual evaluation of COPD: study design, chest CT findings and concordance with quantitative evaluation. Copd. 2012;9(2):151-159. doi:10.3109/15412555.2 012.654923

29. van Gestel AJ, Steier J. Autonomic dysfunction in patients with chronic obstructive pulmonary disease (COPD). J Thorac Dis. 2010;2(4):215-222.

30. Troosters T, Vilaro J, Rabinovich R, et al. Physiological responses to the 6-min walk test in patients with chronic obstructive pulmonary disease. Eur Respir J. 2002;20(3):564-569. doi:10.1183/0903193 6.02.02092001

31. Hogg JC, Chu F, Utokaparch S, et al. The nature of small-airway obstruction in chronic obstructive pulmonary disease. $N$ Engl J Med. 2004;350(26):2645-2653. doi:10.1056/NEJMoa032158

32. Hogg JC. Pathophysiology of airflow limitation in chronic obstructive pulmonary disease. Lancet. 2004;364(9435):709-721. doi:10.1016/S0140-6736(04)16900-6

33. Hasegawa M, Nasuhara Y, Onodera Y, et al. Airflow limitation and airway dimensions in chronic obstructive pulmonary disease. Am J Respir Crit Care Med. 2006;173(12):1309-1315. doi:10.1164/ rccm.200601-037OC

34. Nakano Y, Muro S, Sakai H, et al. Computed tomographic measurements of airway dimensions and emphysema in smokers. Correlation with lung function. Am J Respir Crit Care Med. 2000;162(3 Pt 1):1102-1108. doi:10.1164/ajrccm.162.3.9907120

35. Schroeder JD, McKenzie AS, Zach JA, et al. Relationships between airflow obstruction and quantitative CT measurements of emphysema, air trapping, and airways in subjects with and without chronic obstructive pulmonary disease. AJR Am J Roentgenol. 2013;201(3): W460-470. doi:10.2214/AJR.12.10102

36. Ostridge K, Williams NP, Kim V, et al. Relationship of CT-quantified emphysema, small airways disease and bronchial wall dimensions with physiological, inflammatory and infective measures in COPD. Respir Res. 2018;19(1):31. doi:10.1186/s12931-018-0734-y
37. Thurlbeck WM, Müller NL. Emphysema: definition, imaging, and quantification. AJR Am J Roentgenol. 1994;163(5):1017-1025. doi:10.2214/ajr.163.5.7976869

38. Barbera JA, Ramirez J, Roca J, Wagner PD, Sanchez-Lloret J, Rodriguez-Roisin R. Lung structure and gas exchange in mild chronic obstructive pulmonary disease. Am Rev Respir Dis. 1990;141(4 Pt 1):895-901. doi:10.1164/ajrccm/141.4_Pt_1.895

39. Shiroishi R, Kitagawa C, Miyamoto N, et al. Heart rate recovery after the 6-min walk test is related to 6-min walk distance and percutaneous oxygen saturation recovery in patients with COPD. Respirology. 2015;20(4):671-673. doi:10.1111/resp.12510

40. Yuan W, Nie S, Wang H, Xu Q, Jia N. Anticholinergics aggravate the imbalance of the autonomic nervous system in stable chronic obstructive pulmonary disease. BMC Pulm Med. 2019;19(1):88. doi:10.1186/ s12890-019-0848-0

41. Sajadieh A, Nielsen OW, Rasmussen V, Hein HO, Abedini S, Hansen JF. Increased heart rate and reduced heart-rate variability are associated with subclinical inflammation in middle-aged and elderly subjects with no apparent heart disease. Eur Heart J. 2004;25(5):363-370. doi:10.1016/j.ehj.2003.12.003

42. Subramanian DR, Gupta S, Burggraf D, et al. Emphysema- and airway-dominant COPD phenotypes defined by standardised quantitative computed tomography. Eur Respir J. 2016;48(1):92-103. doi:10.1183/13993003.01878-2015

43. Sterk PJ. Chronic diseases like asthma and COPD: do they truly exist? Eur Respir J. 2016;47(2):359-361. doi:10.1183/139930 03.01930-2015

44. Rodriguez-Roisin R, Rabe KF, Vestbo J, Vogelmeier C, Agustí A. Global Initiative for Chronic Obstructive Lung Disease (GOLD) 20th Anniversary: a brief history of time. Eur Respir J. 2017;50 (1):1700671. doi:10.1183/13993003.00671-2017

\section{Publish your work in this journal}

The International Journal of COPD is an international, peer-reviewed journal of therapeutics and pharmacology focusing on concise rapid reporting of clinical studies and reviews in COPD. Special focus is given to the pathophysiological processes underlying the disease, intervention programs, patient focused education, and self management protocols. This journal is indexed on PubMed Central, MedLine and CAS. The manuscript management system is completely online and includes a very quick and fair peer-review system, which is all easy to use. Visit http://www.dovepress.com/testimonials.php to read real quotes from published authors. 